\title{
Effects of adult nutrition on female reproduction in a fruit-feeding butterfly: The role of fruit decay and dietary lipids
}

\author{
Stephanie S. Bauerfeind*, Klaus Fischer, Steffi Hartstein, \\ Susann Janowitz, Dominik Martin-Creuzburg
}

Department of Animal Ecology I, University of Bayreuth, P.O. Box 101 251, D-95440 Bayreuth, Germany

\begin{abstract}
It was generally believed that butterflies and other holometabolous insects rely primarily on reserves accumulated during the larval stage for reproduction. Recent studies, however, highlight the often fundamental importance of adult nutrition to realize the full reproductive potential. While the importance of carbohydrates is fairly well understood, the role of most other adult-derived substances is only partially resolved. We here focus on the effects of dietary lipids (cholesterol, polyunsaturated fatty acids) and fruit decay (dietary yeast, ethanol) on female reproduction in the tropical, fruit-feeding butterfly Bicyclus anynana (Nymphalidae). We found that banana-fed control females outperformed all other groups fed on sucrose-based diets. Lipids, yeast or ethanol added to a sugar solution did not yield a similarly high reproductive output compared to fruit-fed females. Groups fed fresh or decaying banana showed no differences in reproductive performance. As we could not identify a single pivotal substance, we conclude that resource congruence (the use of nutrient types in a specified ratio) rather than any specific nutrient component is of key importance for maximum reproductive output. Further, dietary quality may affect egg hatching success in spite of no obvious effects on egg size and number. Thus, any implications about potential fitness effects of different diets need to consider egg (and hatchling) viability in addition to fecundity.
\end{abstract}

(C) 2007 Elsevier Ltd. All rights reserved.

Keywords: Sterol; Polyunsaturated fatty acid; Yeast; Ethanol; Egg size

\section{Introduction}

Many holometabolous insects, as e.g. Lepidoptera, were generally believed to rely primarily on nutrients accumulated during the larval stage for reproductive output (Leather, 1995; Telang et al., 2001; Mevi-Schütz and Erhardt, 2003) neglecting the indispensable function of adult feeding for reproductive success in at least some insect species (e.g. Gilbert, 1972; Braby and Jones, 1995; Rusterholz and Erhardt, 2000; Bauerfeind and Fischer, 2005a). While the often crucial importance of adult-derived carbohydrates for female butterfly reproduction is fairly well understood (e.g. Leather, 1984; Wei et al., 1998; Fischer et al., 2004; O'Brien et al., 2004; Bauerfeind and

\footnotetext{
*Corresponding author. Tel.: + 49921 553079; fax: + 49921552784.

E-mail address: stephanie.bauerfeind@uni-bayreuth.de (S.S. Bauerfeind).
}

Fischer, 2005b), the role of most other adult-derived substances is still only partially resolved (e.g. DunlapPianka et al., 1977; Murphy et al., 1983; Moore and Singer, 1987; Hill and Pierce, 1989; Boggs and Jackson, 1991; Smedley and Eisner, 1996).

Lipids, for instance, are likely to be of key importance for insect reproduction, as they are major constituents of the oocyte dry mass and serve various functions including their role as the main energy source for the developing embryo (Stanley-Samuelson and Loher, 1983; StanleySamuelson et al., 1988; Kawooya and Law, 1988; Svoboda, 1999; Ziegler and Van Antwerpen, 2006). As most insects are neither able to synthesize long-chain polyunsaturated fatty acids (hereafter PUFAs; but Blomquist et al., 1982; Beenakkers et al., 1985) nor the tetracyclic steroid nucleus required for the synthesis of sterols (Behmer and Nes, 2003) de novo, they depend on exogenous sources for successful development and reproduction (Al-Izzi and 
Hopkins, 1982; Beenakkers et al., 1985; Turunen, 1990; Behmer and Grebenok, 1998; Svoboda, 1999; Mondy and Corio-Costet, 2000). In butterflies, lipid requirements are thought to be mainly covered by larval-derived storage depots in the fat body (Behmer and Grebenok, 1998; Arrese et al., 2001). Fruit-feeding butterflies, though, may have access to noticeable amounts of adult-derived lipids, whose importance, in contrast to larval-derived ones, is currently unknown.

Apart from being in themselves a source of various substances including lipids (cf. University of Hohenheim, 1996), fruits also support the growth of microorganisms and fungi (associated with the production of fermentative products like organic acids and alcohols; Morais et al., 1995; Molleman et al., 2005a). Among these yeast is of special concern, providing protein and other substances to insect frugivores (Rattray et al., 1975; Morais et al., 1995; Brown et al., 1996; Good and Tatar, 2001). As a dietary supplement, yeast has been shown to dramatically increase egg production but to reduce longevity in Drosophila melanogaster and Chrysoperla carnea (Chippindale et al., 1993; McEwen and Kidd, 1995; Simmons and Bradley, 1997; Good and Tatar, 2001).

The fermenting activity of yeasts results in the production of noticeable concentrations of e.g. ethanol (Leavey, 2004). While low levels of ethanol are present in fruits of all developmental stages (ranging from trace amounts up to $0.5 \%$; Dominy, 2004), its concentration rises more than tenfold during fermentation (Bokor and Pecsenye, 2000; Dudley, 2004; Milton, 2004). Ethanol at low concentrations may serve as an energy source (apart from being an olfactory cue; e.g. Omura and Honda, 2003), while high concentrations $(>5.0-7.5 \%)$ are toxic (Bokor and Pecsenye, 2000; Heberlein et al., 2004). Adaptation to environmental alcohol has been extensively studied in Drosophila only (e.g. McKenzie and McKechnie, 1979; Bokor and Pecsenye, 2000; Fry, 2001), while comparable studies in other insect species are largely lacking (but see Abramson et al., 2005).

In summary, our understanding of the effects of adult diet on insect life history traits (survival and reproduction) is still far from being complete. We here focus on the relative importance of different compounds of the adult diet for reproduction in the tropical, fruit-feeding butterfly Bicyclus anynana (Butler, 1879) (Lepidoptera: Nymphalidae). In this species adult-derived carbohydrates are essential for egg production, without which no eggs will be produced (Fischer et al., 2004; Bauerfeind and Fischer, 2005b). When feeding on fruit (banana), female $B$. anynana deposited more and larger eggs than females feeding on a pure sucrose solution (Bauerfeind and Fischer, $2005 \mathrm{~b}$ ). As neither amino acids nor various micronutrients (vitamins, minerals) account for this discrepancy (Bauerfeind and Fischer, 2005b), it is currently unclear whether the better performance of fruit-fed butterflies is caused by one critical, yet unidentified class of substances (e.g. lipids), a whole variety of substances contributing small effects each, or some volatile feeding cues increasing intake rates.

Against this background we performed two separate experiments focussing on fitness effects (rather than preferences that may not necessarily indicate a fitness advantage) of adult-derived nutrients of female $B$. anynana . While in experiment 1 we focus on the effects of dietary compounds acquired during the process of decay (yeast, ethanol), experiment 2 investigates the effects of adultderived cholesterol and PUFAs on survival and reproductive output of female butterflies. Additionally, the effects of diet composition on egg hatching success are investigated.

\section{Methods}

\subsection{Study organism}

B. anynana is a tropical, fruit-feeding butterfly ranging from Southern Africa to Ethiopia (Larsen, 1991). The species exhibits striking phenotypic plasticity (two seasonal morphs), which is thought to function as an adaptation to alternate wet-dry seasonal environments and the associated changes in resting background and predation (Brakefield, 1997; Lyytinen et al., 2004). A laboratory stock population was established at Bayreuth University, Germany, in 2003 from several hundred individuals derived from a well-established stock population at Leiden University, The Netherlands. The Leiden population was founded in 1988 from 80 gravid females caught at a single locality in Malawi. In each generation several hundred individuals are reared maintaining high levels of heterozygosity at neutral loci (Saccheri and Bruford, 1993; Van't Hof et al., 2005). For this study butterflies from the Bayreuth stock population were used.

\subsection{Experimental design}

All butterflies were reared and maintained in an environmental cabinet at a constant temperature of $27^{\circ} \mathrm{C}$, high relative humidity $(70 \%)$ and a photoperiod of L12:D12 (24h light:dark cycle). These conditions are similar to those at which the butterflies develop and reproduce during the favourable wet season in the field (Brakefield, 1997). Larvae were reared in big population cages $(50 \times 50 \times 50 \mathrm{~cm})$ containing potted maize plants in ample supply, which were replaced if necessary. Pupae were removed daily from the rearing cages, transferred to a separate cage and checked daily for eclosed butterflies. Males and females were separated on the day of adult eclosion (note that male $B$. anynana butterflies do not mate on their first day). All males were pooled and given access to moist banana, while females were randomly assigned to different dietary treatments as described below. All males were provided the same diet to exclusively investigate effects of female nutrition on reproduction. Note that $B$. anynana males are not providing females with nuptial gifts, and that there is no evidence for any effects of male 
treatment on female reproductive output (Fischer et al., 2003; Ferkau and Fischer, 2006). Females were given a premating time of 1 and 2 days (experiments 1 and 2, respectively) separated from males, after which an equal number of random virgin males was added to the females' cages for 2 days. After the mating period females were placed individually in translucent plastic pots $(11$, covered with gauze) containing a fresh cutting of maize for egg laying. Thus, oviposition started for all females on day 4 or 5 (experiments 1 and 2, respectively) of adult life. Eggs were collected, counted and measured every other day until the death of the butterflies or until day 12 of the oviposition period (experiments 1 and 2, respectively).

\subsubsection{Experiment 1}

Upon eclosion females were divided among the following five treatment groups ( $n=55-57$ each): access to (1) a pure sucrose solution, (2) a sucrose solution supplemented with baker's yeast (Saccharomyces cervisiae), (3) a sucrose solution supplemented with ethanol $(2 \mathrm{vol} \%)$, (4) fresh moist banana mash or (5) decaying moist banana mash that was allowed to decompose for 3 days at $27^{\circ} \mathrm{C}$ and a relative humidity of $70 \%$ prior to the experiment. Throughout, the applied sucrose concentration was $20 \mathrm{vol} \%$. Note that fresh banana contains approximately $20 \%$ total carbohydrates (at $75 \%$ water content, cf. University of Hohenheim, 1996). Thus, all feeding treatments provide the butterflies with comparable amounts of carbohydrates. Feeding solutions were replaced every other day. Additionally, all females had access to water throughout. Females were fed on the respective diets throughout their lives, i.e. from the eclosion day onwards.

\subsubsection{Experiment 2}

As the above and an earlier experiment demonstrated a significantly higher reproductive output in banana-fed females as compared to all sugar-based solutions (cf. Bauerfeind and Fischer, 2005b), we doubled the sucrose concentration in all sugar-based treatment groups to $40 \mathrm{vol} \%$ in order to rule out that the effect was due to an energetic constraint. Females were assigned to the following seven treatment groups ( $n=39-51$ each): access to (1) a pure sucrose solution, (2) a sucrose solution enriched with liposomes $(10 \mu \mathrm{l}$ liposome solution in $2 \mathrm{ml}$ sucrose solution; ca. $1 \times 10^{6}$ liposomes $/ \mathrm{ml}$ suspension; see below) (hereafter liposomes), (3) a sucrose solution enriched with liposomes supplemented with cholesterol (hereafter cholesterol), (4) a sucrose solution enriched with liposomes supplemented with a mixture of PUFAs (a balanced mixture of $\alpha$-linolenic acid 18:3(n-3), linoleic acid 18:2(n-6), arachidonic acid 20:4(n-6) and eicosapentaenoic acid 20:5(n-3)), (5) fresh moist banana, (6) a sucrose solution enriched with ethanol ( $5 \mathrm{vol} \%$ ) (hereafter EtOH) or (7) a sucrose solution enriched with baker's yeast (S. cervisiae) (hereafter yeast). The latter two were once again included to investigate effects of dietary quality on egg hatching success (see below). Feeding solutions were daily supplemented with liposomes and ethanol and replaced every other day. Again, all females had access to water throughout.

In this experiment, egg hatching success was scored at the beginning of (days 1-4 of the Liposome stock suspensions were prepared from $3 \mathrm{mg}$ 1-palmitoyl-2oleoyl-phosphatidylglycerol and $7 \mathrm{mg}$ 1-palmitoyl-2oleoyl-phosphatidylcholin (Lipoid, Germany) dissolved in an aliquot of chloroform. Cholesterol- or PUFA-containing liposomes were prepared by adding $3.33 \mathrm{mg}$ of cholesterol or PUFA mixture (a balanced mixture of linoleic acid 18:2(n-6), $\alpha$-linolenic acid 18:3(n-3), arachidonic acid 20:4(n-6) and eicosapentaenoic acid 20:5(n-3)) from lipid stock solutions $(2.5 \mathrm{mg} / \mathrm{ml}$ chloroform). The resulting suspensions were dried using a rotary evaporator, dissolved in $10 \mathrm{ml}$ buffer $(20 \mathrm{mmol} / 1 \mathrm{NaPi}, 150 \mathrm{mmol} / 1 \mathrm{NaCl}$, $\mathrm{pH}$ 7) and incubated on a rotary shaker $(100 \mathrm{rev} / \mathrm{min})$ for $30 \mathrm{~min}$. Subsequently, the liposome suspensions were sonicated in an ultrasonic bath and excess free cholesterol and PUFAs were removed by washing the liposomes in fresh buffer using an ultra-speed centrifuge $(150.000 \times g$, $90 \mathrm{~min}, 4^{\circ} \mathrm{C}$ ). Prior to the addition of liposomes to the experimental feeding solutions, the liposome stock suspensions were again sonicated for $2 \mathrm{~min}$. Mean concentrations $( \pm 1$ SE) per $100 \mu$ liposome solution were: cholesterol: $12.6 \pm 0.2 \mu \mathrm{g}$; PUFAs: linoleic acid $6.2 \pm 0.1 \mu \mathrm{g}$; linolenic acid $6.3 \pm 0.1 \mu \mathrm{g}$; arachidonic acid $7.8 \pm 0.1 \mu \mathrm{g}$; eicosapentaenoic acid $7.3 \pm 0.03 \mu \mathrm{g}$. Mean diameter of a liposome was $4.2 \pm 0.2 \mu \mathrm{m}$. Thus, the intake of liposomes by the butterflies is not constrained by proboscis morphology (Molleman et al., 2005b).

In this experiment, egg hatching success was scored at the beginning of (days 1-4 of the oviposition period) and later in the oviposition period (days 8-11). Therefore, eggs of 32-44 females per treatment group were collected and placed, separated by female, in Petri dishes lined with moist filter paper and a small cutting of maize for hatching caterpillars. On average, $42.5 \pm 0.9$ and $26.4 \pm 0.7$ eggs per female (mean \pm 1 SE) were collected at the beginning and later in the oviposition period, respectively. The number of hatching caterpillars was recorded daily until no more hatchlings were found on 2 consecutive days.

\subsection{Data analysis}

As the eggs of $B$. anynana are nearly perfect spheres, egg size was measured as cross-sectional area $\left(\mathrm{mm}^{2}\right)$ using a digital camera (Leica DC300) connected to a binocular microscope. The resulting images were analysed using Scion Image public software (Scion Corporation, 2000). Tight correlations between egg area (applying image analysis) and egg mass as well as hatchling size confirm that this method provides a highly reliable measurement of egg size in B. anynana (Fischer et al., 2002). To calculate egg size for individual females, the mean across all measurement days was used as between-day variation in egg size was negligible. 
Data were analysed using one-way ANOVAs throughout; significant differences between treatment groups were identified using Tukey's HSD. As ANOVA requirements were not met in all cases, data were re-analysed using the non-parametric Kruskal-Wallis test, which did not reveal any qualitative differences from the ANOVA results (results not shown). Data on egg numbers and sizes over time were analysed using repeated-measurement ANOVAs. Survival times were scored using Mantel's procedure (Mantel, 1967) followed by a $\chi^{2}$-test (based on sum of scores) to test for significance. Hatching success was assessed using nominal logistic regressions on binary data, separately for early and late eggs. Females whose eggs did not hatch at all (assuming that eggs were not fertilized) and females without available data for both time periods (early and late eggs) were excluded from the analyses. All statistical tests were performed using Statistica 6.1 (StatSoft Inc., 2003). Throughout the text all means are given \pm 1 SE.

\section{Results}

\subsection{Experiment 1}

Adult diet significantly affected survival probability $\left(\chi_{4}^{2}=31.2, P<0.001\right)$, longevity $\left(F_{4,264}=10.0, P<0.001\right)$, lifetime fecundity $\left(F_{4,264}=6.1, P<0.001\right)$ and mean egg size $\left(F_{4,263}=10.7, P<0.001\right)$ of $B$. anynana females. Longevity and survival were highest in banana-fed females, while females having had access to yeast exhibited the lowest longevity (Table 1, Fig. 1a). Lifetime fecundity was highest in banana-fed females, intermediate in the groups fed on sucrose or sucrose enriched with ethanol and lowest in females fed on sucrose supplemented with yeast (Table 1). In contrast to the above results, a repeatedmeasurement ANOVA on egg numbers over time (until oviposition day 12) revealed no significant influence of dietary quality $\left(F_{4,228}=1.0, P=0.416\right)$, indicating that the difference in lifetime fecundity can be attributed to bananafed females depositing higher egg numbers during the late oviposition period (significant interaction between time and diet: $\left.F_{20,1140}=2.1, P=0.003\right)$. In all dietary groups egg numbers declined with increasing female age $\left(F_{5,1140}=\right.$ 59.3, $P<0.001)$, with the decrease being more accentuated in the sucrose-based (i.e. a pure sucrose solution and sucrose solutions supplemented with liposomes, cholesterol, PUFAs, ethanol or yeast) than in both banana groups (Fig. 2a).

Egg size was largest in banana-fed females, followed by yeast- and ethanol-fed ones which were statistically indistinguishable, while females fed on a pure sucrose solution produced the smallest eggs (Table 1). A repeatedmeasurement ANOVA on egg sizes over time (until oviposition day 12) revealed that egg sizes generally declined with increasing female age $\left(F_{5,650}=5.3\right.$, $P<0.001$ ), which was restricted to females feeding on sucrose-based solutions. Banana-fed females showed the

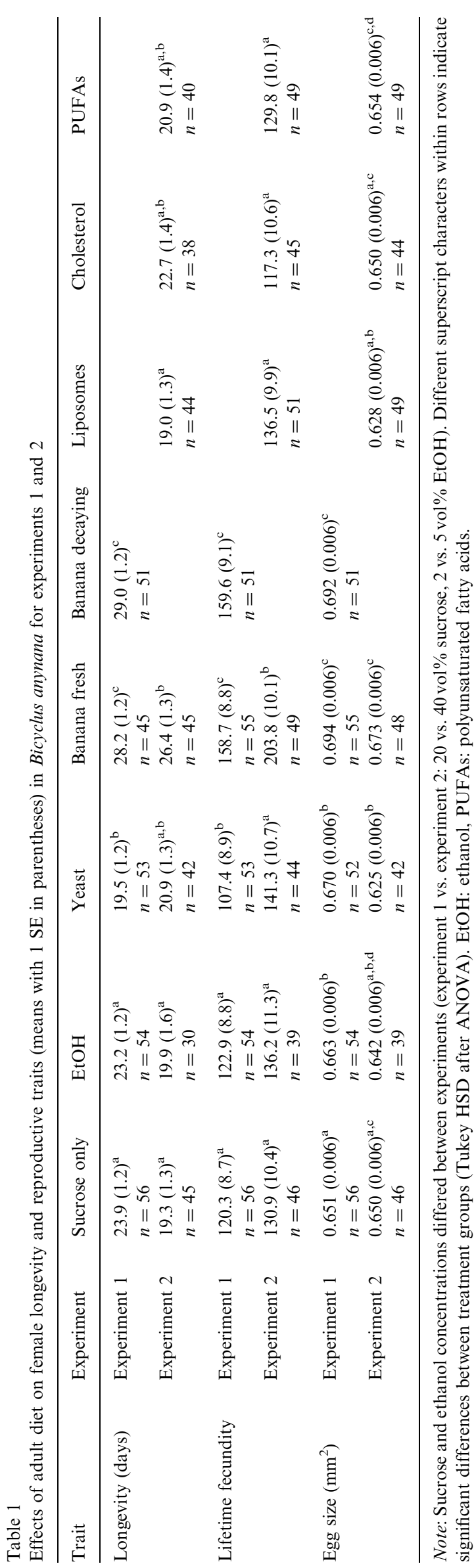




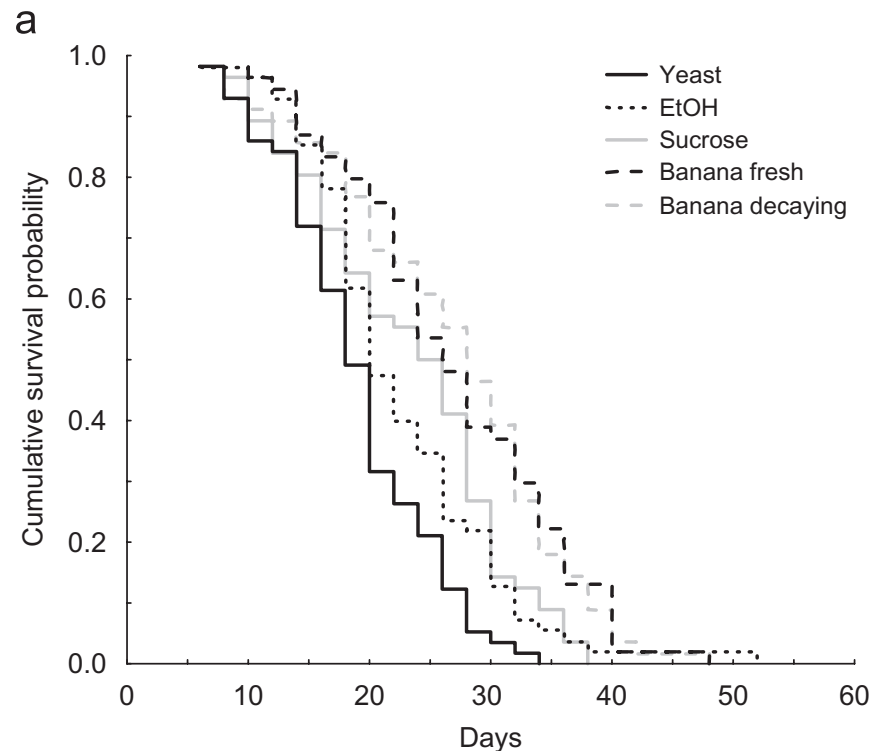

b

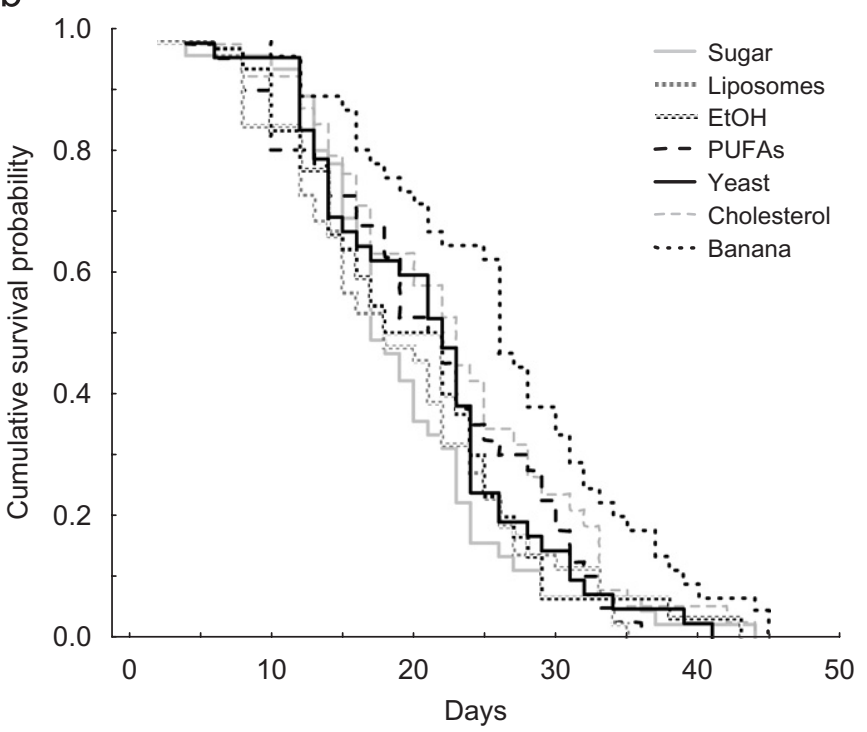

Fig. 1. Cumulative survival probabilities of female Bicyclus anynana fed on different diets for experiments 1 (a) and 2 (b). EtOH: ethanol, PUFAs: polyunsaturated fatty acids.

opposite trend (significant interaction between time and diet: $F_{20,650}=3.5, P<0.001$, see Fig. 3 a).

\subsection{Experiment 2}

Similar to above, adult diet significantly affected survival probability $\left(\chi_{6}^{2}=19.5, P=0.003\right)$, longevity $\left(F_{6,277}=3.8\right.$, $P=0.001$ ), fecundity (until day 12 of the oviposition period: $\left.F_{6,316}=7.7, \quad P<0.001\right)$ and mean egg size $\left(F_{6,310}=8.0, P<0.001\right)$ of $B$. anynana females. Again, survival and longevity were higher in banana-fed females compared to the groups fed on sucrose-based solutions (Table 1, Fig. 1b). Likewise, fecundity was significantly higher in females feeding on moist banana than on any other diet, with the advantage being accumulated throughout the oviposition period (Table 1, Fig. 2b). Throughout,
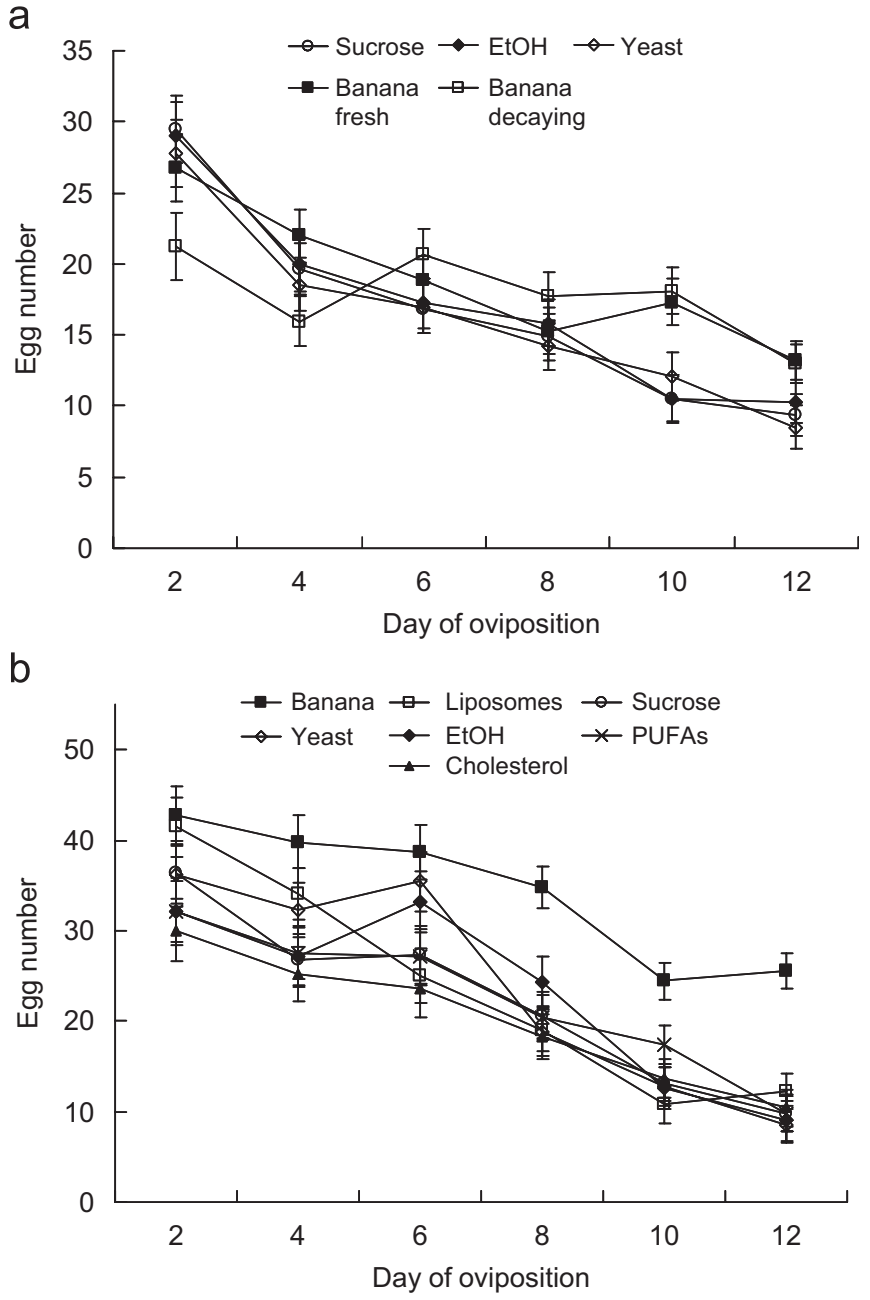

Fig. 2. Egg number over time (group means $\pm 1 \mathrm{SE}$ ) for female Bicyclus anynana fed on different diets for experiments 1 (a) and 2 (b). EtOH: ethanol, PUFAs: polyunsaturated fatty acids.

egg numbers declined with increasing female age (repeatedmeasurement ANOVA: $\left.F_{5,1410}=102.7, P<0.001\right)$, with the decrease being less pronounced in banana-fed females than in females fed on sucrose-based diets (significant interaction between time and dietary treatment: $F_{30,1410}=1.6, P=0.019$, see Fig. $2 b$ ).

Egg size was largest in banana-fed females and smallest in females fed on sucrose-based solutions supplemented with liposomes or yeast (Table 1). Overall, differences in egg size among the sugar-based treatment groups were rather small (for significant differences between treatment groups see Table 1). Throughout, egg sizes declined with increasing female age (repeated-measurement ANOVA: $\left.F_{5,740}=30.1, \quad P<0.001\right)$ except for banana-fed females (significant interaction between time and dietary treatment: $F_{30,740}=3.3, P<0.001$, Fig. $\left.3 b\right)$.

Hatching success did not differ significantly among treatment groups for first eggs (Wald $\chi_{6}^{2}=11.5$, $P=0.070$ ), but it did so for late eggs (Wald $\chi_{6}^{2}=40.8$, $P<0.001$, see Fig. 4). At this stage, eggs from females fed 
a

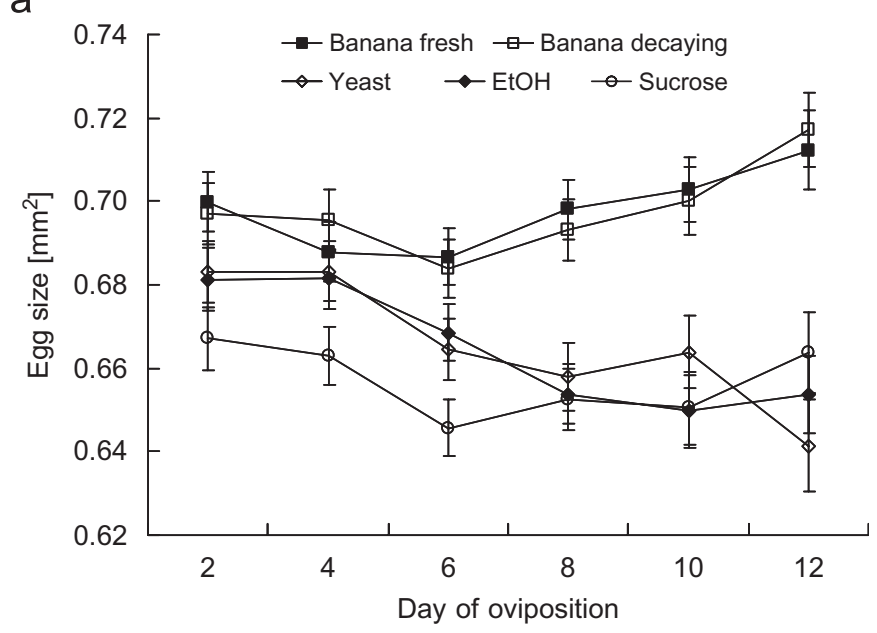

b

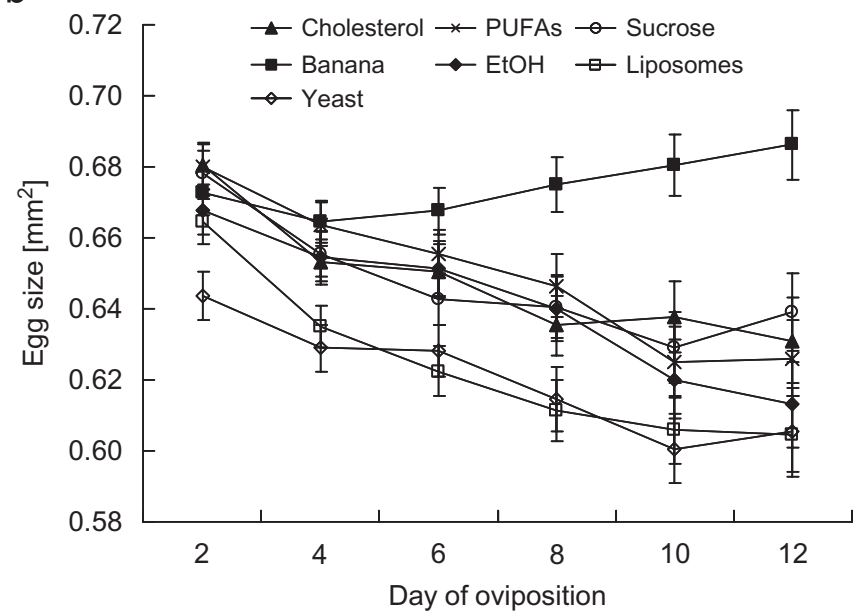

Fig. 3. Egg size over time (group means \pm 1 SE) for female Bicyclus anynana fed on different diets for experiments 1 (a) and 2 (b). EtOH: ethanol, PUFAs: polyunsaturated fatty acids.

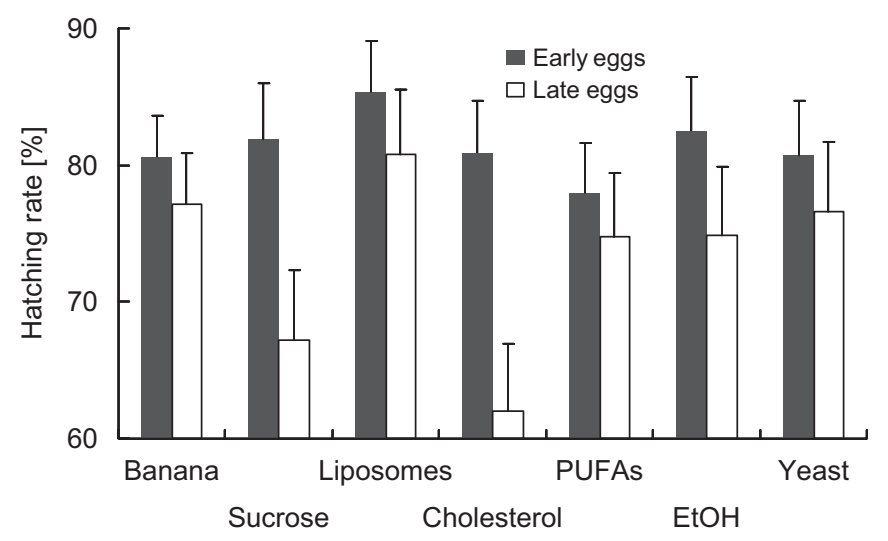

Fig. 4. Hatching success of early and late eggs (group means \pm 1 SE) of Bicyclus anynana fed on different diets $(n=19-35)$. EtOH: ethanol, PUFAs: polyunsaturated fatty acids.

on a pure or cholesterol-supplemented sucrose solution showed a clearly reduced hatching success. Throughout, hatching success was lower for late compared to first eggs.

\section{Discussion}

\subsection{Effects on longevity and reproduction}

When feeding on banana, characterized by a complex nutritional composition, female $B$. anynana had longer life spans, larger egg sizes and a higher fecundity as compared to females fed on sucrose-based solutions with various admixtures (Table 1, see also Bauerfeind and Fischer, 2005b). This study was aimed at disentangling the causes underlying this tremendous gain in reproductive output. As earlier experiments could largely rule out that amino acids or micronutrients such as minerals or vitamins play a decisive role (Bauerfeind and Fischer, 2005b), we focussed in experiment 1 on processes associated with the decay of fruit. Two lines of evidence suggest that the increased reproductive output in banana-fed females is not associated with such processes. First, performance was independent of the stage of fruit decay, as females feeding on fresh or decaying banana were statistically indistinguishable. Second, neither supplementation with yeast (mimicking fermentative products of proven value to insect frugivores) nor alcohol (as a likely volatile attractant) enhanced reproductive output or longevity as compared to a pure sugar solution.

These findings imply that at least during this early stage of decay fresh and decaying banana were of very similar quality for $B$. anynana female. Our data cannot rule out an effect of feeding on decaying fruit at later stages of fruit decomposition, characterized by a depletion of simple sugars and shifts in the community structure of microorganisms associated with increasing amounts of fermentative products like organic acids and alcohols (Morais et al., 1995; Dominy, 2004; Dudley, 2004). Yet, this remains to be experimentally tested, but appears rather unlikely based on the current results (cf. the results from yeast supplementation).

In principle, activities of microorganisms and fungi may provide additional resources that are able to enhance insect reproductive output. Accordingly, incorporation of yeast has been shown to dramatically increase egg production in various insect species, accompanied by a decreased life span (Chippindale et al., 1993; McEwen and Kidd, 1995; Simmons and Bradley, 1997; Good and Tatar, 2001). Likewise, feeding on a sucrose solution supplemented with yeast resulted in a significant reduction in longevity in $B$. anynana (in experiment 1), though without any positive effect on reproduction. Interestingly, female survival was not reduced in experiment 2 that included a higher sucrose concentration. This suggests that females feeding on a higher concentrated sucrose solution may need to imbibe less fluid and thus a lesser amount of presumably detrimental yeast-derived compounds in order to obtain the same amount of energy as compared to females that feed on a less concentrated sucrose solution. Yet, this needs to be verified in further experiments controlling for food consumption rates. Similarly, Bauerfeind and Fischer 
(2005b) showed that dietary amino acids led to a decrease in female longevity and survival probability without reproductive benefits.

When interpreting these findings, it should be borne in mind, though, that both larval and adult diets seem to strongly interact with each other to fully meet all nutritional requirements of insects (Bauerfeind and Fischer, 2005a) and all individuals in this experiment were abundantly fed during the larval stage. Under such conditions larval-derived (nitrogenous, but also lipid, see below) reserves seem to be already sufficient to realize full reproductive potential. This picture may change substantially when storage reserves are reduced due to larval food shortage. In that case, adult-derived amino acid intake has indeed been found to enhance reproduction in a butterfly (Jervis and Boggs, 2005; Mevi-Schütz and Erhardt, 2005). Thus, the nutritional status may yield striking effects on the use of and need for adult-derived nitrogenous compounds. Similar considerations may hold for lipid stores under larval food restriction (see below).

When feeding on decaying fruit, butterflies also imbibe fermentative products associated with the metabolic activities of the fungi, of which ethanol is the most prominent (Omura et al., 2000; Omura and Honda, 2003; Leavey, 2004). Depending on its concentration ethanol either serves as an energy source or as a toxin in Drosophila (Bokor and Pecsenye, 2000; Heberlein et al., 2004). In $B$. anynana female survival and reproduction remained unaffected by dietary ethanol. This suggests that on the one hand the butterflies are able to deal with physiologically relevant concentrations of ethanol (see Bokor and Pecsenye, 2000), but on the other hand do not gain from having access to this additional energy source. Further, the lack of effect suggests that ethanol, acting as a feeding cue in B. anynana and other Lepidoptera (e.g. Omura et al., 2000; Omura and Honda, 2003), does not increase intake rates which in turn may affect reproductive output.

In experiment 1 as well as in an earlier study (Bauerfeind and Fischer, 2005b), we applied a sucrose concentration of $20 \mathrm{vol} \%$. However, maximum rates of energy gains have been reported for sugar concentrations of 30-50\% (Hainsworth et al., 1991; May, 1985; Boggs, 1988), implying that the lack of response to any additional nutritive compound might be due to a mere energetic constraint. Yet, butterflies were not limited in the amount of feeding solution offered, enabling them to imbibe adequate volumes of the dietary solution to fully meet their energetic requirements (Boggs, 1988; Hainsworth et al., 1991). To entirely exclude the possibility of energetic restrictions we provided the butterflies with dietary sucrose solutions of $40 \mathrm{vol} \%$ in experiment 2 (being substantially higher than the carbohydrate content of banana), which did not change any of the results qualitatively.

Thus far, we could largely rule out that the enhanced reproductive output of fruit-fed $B$. anynana females is caused by processes associated with the decay of fruit, feeding preferences and associated changes in intake rates, energetic constraints imposed by artificial diets or minerals and vitamins (current results and see Bauerfeind and Fischer, 2005b). As insect eggs need to be provided with relatively large amounts of lipids stemming from exogenous sources (Kawooya and Law, 1988; Ziegler and Van Antwerpen, 2006), lipids may well be involved in triggering the increased reproductive output of fruit-fed females. Nevertheless, we could not detect any beneficial effect of adult-derived cholesterol or PUFAs on female survival and reproductive output.

Cholesterol - as the major sterol found in insects-has been shown to meet the total sterol requirements of many insects with only a few exceptions (Dadd, 1973; Canavoso et al., 2001 and references therein; Behmer and Nes, 2003). Thus, dietary cholesterol is likely to be fully suitable for metabolic utilization by female $B$. anynana. Note that, despite of no effects on the quantity and size of eggs, feeding on cholesterol did affect egg hatching success (see below). Similarly, the lack of any effects of adult-derived PUFAs on female reproduction is surprising, as access to PUFAs during the larval stage is essential for normal development and realization of the full reproductive potential later in life (see Beenakkers et al., 1985; Stanley-Samuelson et al., 1988; Canavoso et al., 2001 for reviews). We here provided adult female butterflies with a mixture of linoleic acid, linolenic acid, arachidonic acid and eicosapentaenoic acid. Linoleic and linolenic acids are the most abundant PUFAs found in caterpillars and adult butterflies (Wang et al., 2006), and both are thought to adequately satisfy the nutritional need for PUFAs in most species (Canavoso et al., 2001 and references therein). Further, they are considered essential fatty acids for many insect species (Beenakkers et al., 1985). Eicosapentaenoic acid and arachidonic acid contribute to the synthesis of prostaglandins (Turunen and Pärnänen, 1987) which are implicated in insect reproduction (Loher et al., 1981; Beenakkers et al., 1985).

The lack of response to cholesterol or PUFAs from adult feeding suggests that adult-derived lipids are not a determining factor for reproductive output in this species, even though lipids are likely to be of crucial importance during the larval stage. Thus, either the applied lipid concentrations were too small to elicit noticeable effects or-more likely - all lipid requirements of adult female B. anynana are usually met by stored resources derived from larval feeding.

The observed gain in reproductive output when feeding on banana could be the result of increased intake rates based on an intrinsic preference for bananas (due to e.g. odour, see e.g. Honda et al., 1998; Andersson, 2003 for effects of floral odours on adult butterfly feeding response). Note, however, all females were facing no-choice situations with only one food source being provided, which was easily and abundantly available. Thus, it is not obvious why females should feed less than needed even if they would prefer a different diet when given a choice. 


\subsection{Effects on egg hatching success}

Considering exclusively the size and number of eggs may be insufficient to assess fitness effects, which may also depend to a large extent on offspring viability. Therefore, survival rates among the offspring produced by females from different nutritional treatments were compared during early development, i.e. in the egg stage. In B. anynana as well as in many other insect species egg to adult survival is largely determined by egg hatching rates and neonate survival (e.g. Jann and Ward, 1999; Fox et al., 2003). Hatching rates of eggs deposited early in the oviposition period were very similar across dietary treatment groups. Thus, shortly after eclosion all females were able to produce high-quality eggs, ensuring a high hatching success throughout. With increasing female age hatching rates declined, with the decrease being more accentuated in females fed on a pure or on a cholesterol-supplemented sucrose solution.

This suggests that, when not adequately fed, females may run short of some specific nutrients initially available from larval stores, which are required to ensure maximum hatching success (see also Fox, 1993; Yanagi and Miyatake, 2002). Adequate nutrition is provided by banana, but more interestingly also by sugar solutions supplemented with liposomes (probably serving as a source of phospholipids), PUFAs (though it cannot be distinguished whether this effect is due to liposomes or the provided PUFAs per se), ethanol and yeast. Females fed on cholesterol-supplemented solutions, in contrast, had a rather low hatching success later in the oviposition period. This is odd, indicating an adverse effect of cholesterol which outweighs the beneficial effect of liposomes.

\section{Conclusions}

The high importance of adult income for reproduction in B. anynana does stress the complexity of reproductive resource allocation in holometabolous insects, which were formerly assumed to rely primarily on larval stores (Leather, 1995; Telang et al., 2001; Mevi-Schütz and Erhardt, 2003). The large advantage of feeding on fruit compared to sugar solutions with various admixtures seems extraordinary (Fischer et al., 2004; Bauerfeind and Fischer, 2005b). Nevertheless, we could not identify a single pivotal substance (in addition to sucrose) that was able to elicit a comparably high reproductive performance as banana, although we tested all major substances known to be involved in insect egg production (cholesterol, PUFAs, nitrogenous compounds; see Bauerfeind and Fischer, 2005b for amino acids and micronutrients). Nevertheless, dietary quality may affect egg quality and thus hatching success (even without any obvious effects on egg numbers and sizes), though this issue needs further investigation. Additionally, we could largely rule out that processes associated with the decay of fruit are responsible for the increased reproductive output of fruit-fed females.
The available evidence clearly suggests that the greatly enhanced reproductive output in banana-fed females is due to a whole variety of substances contributing small effects each, rather than to one single pivotal substance (apart from sucrose; see O'Brien et al., 2004; Fischer et al., 2004). Thus, we conclude that resource congruence (the use of nutrient types in a specified ratio; Bazzaz, 1996; see also O'Brien et al., 2004; Fischer et al., 2004) is the key to answer the question.

\section{Acknowledgements}

We thank Anneke Dierks, Anne Gebhardt and Katharina Lange for experimental assistance and two anonymous reviewers for valuable comments on the manuscript. Financial support was provided by the German Research Council (DFG Grant no. Fi $846 / 1-3$ to K.F. and a scholarship within the Graduate College 678 to Dominik Martin-Creuzburg).

\section{References}

Abramson, C.I., Sanderson, C., Painter, J., Barnett, S., Wells, H., 2005. Development of an ethanol model using social insects: V. Honeybee foraging decisions under the influence of alcohol. Alcohol 36, 187-193.

Al-Izzi, M.A.J., Hopkins, T.L., 1982. Effects of dietary sterols on development and reproduction of southwestern corn borer Diatraea grandiosella Dyar. Journal of Insect Physiology 28, 189-192.

Andersson, S., 2003. Foraging responses in the butterflies Inachis io, Aglais urticae (Nymphalidae), and Gonepteryx rhamni (Pieridae) to floral scents. Chemoecology 13, 1-11.

Arrese, E.L., Canavoso, L.E., Jouni, Z.E., Pennington, J.E., Tsuchida, K., Wells, M.A., 2001. Lipid storage and mobilization in insects: current status and future directions. Insect Biochemistry and Molecular Biology 31, 7-17.

Bauerfeind, S.S., Fischer, K., 2005a. Effects of food stress and density in different life stages on reproduction in a butterfly. Oikos 111, 514-524.

Bauerfeind, S.S., Fischer, K., 2005b. Effects of adult-derived carbohydrates, amino acids and micronutrients on female reproduction in a fruit-feeding butterfly. Journal of Insect Physiology 51, 545-554.

Bazzaz, F., 1996. Plants in Changing Environments: Linking Physiological, Population and Community Ecology. Cambridge University Press, Cambridge.

Beenakkers, A.M.T., Van der Horst, D.J., Van Marrewijk, W.J.A., 1985. Insect lipids and lipoproteins, and their role in physiological processes. Progress in Lipid Research 24, 19-67.

Behmer, S.T., Grebenok, R.J., 1998. Impact of dietary sterols on lifehistory traits of a caterpillar. Physiological Entomology 23, 165-175.

Behmer, S.T., Nes, W.D., 2003. Insect sterol nutrition and physiology: a global overview. Advances in Insect Physiology 31, 1-72.

Blomquist, G.J., Dwyer, L.A., Chu, A.J., Ryan, R.O., De Renobales, M., 1982. Biosynthesis of linoleic acid in a termite, cockroach and cricket. Insect Biochemistry 12, 349-353.

Boggs, C.L., 1988. Rates of nectar feeding in butterflies: effects of sex, size, age and nectar concentration. Functional Ecology 2, 289-295.

Boggs, C.L., Jackson, L.A., 1991. Mud-puddling by butterflies is not a simple matter. Ecological Entomology 16, 123-127.

Bokor, K., Pecsenye, K., 2000. Differences in the effect of ethanol on fertility and viability components among laboratory strains of Drosophila melanogaster. Hereditas 132, 215-227.

Braby, M.F., Jones, R.E., 1995. Reproductive patterns and resource allocation in tropical butterflies: influence of adult diet and seasonal phenotype on fecundity, longevity and egg size. Oikos 72, 189-204. 
Brakefield, P.M., 1997. Phenotypic plasticity and fluctuating asymmetry as responses to environmental stress in the butterfly Bicyclus anynana. In: Bijlsma, R.R., Loeschke, V. (Eds.), Environmental Stress: Adaptation and Evolution. Birkhäuser, Basel, pp. 65-78.

Brown, M.R., Barrett, S.M., Volkman, J.K., Nearhos, S.P., Nell, J.A., Allan, G.L., 1996. Biochemical composition of new yeasts and bacteria evaluated as food for bivalve aquaculture. Aquaculture 143, 341-360.

Canavoso, L.E., Jouni, Z.E., Karnas, K.J., Pennington, J.E., Wells, M.A., 2001. Fat metabolism in insects. Annual Review of Nutrition 21, 23-46.

Chippindale, A.K., Leroi, A.M., Kim, S.B., Rose, M.R., 1993. Phenotypic plasticity and selection in Drosophila life-history evolution. I. Nutrition and the cost of reproduction. Journal of Evolutionary Biology 6, 171-193.

Dadd, R.H., 1973. Insect nutrition: current developments and metabolic implications. Annual Review of Entomology 18, 381-420.

Dominy, N.J., 2004. Fruits, fingers, and fermentation: the sensory cues available to foraging primates. Integrative and Comparative Biology 44, 295-303.

Dudley, R., 2004. Ethanol, fruit ripening, and the historical origins of human alcoholism in primate frugivory. Integrative and Comparative Biology 44, 315-323.

Dunlap-Pianka, H., Boggs, C.L., Gilbert, L.E., 1977. Ovarian dynamics in Heliconiine butterflies: programmed senescence versus eternal youth. Science 197, 487-490.

Ferkau, C., Fischer, K., 2006. Costs of reproduction in male Bicyclus anynana and Pieris napi butterflies: effects of mating history and food limitation. Ethology 112, 1117-1127.

Fischer, K., Zwaan, B.J., Brakefield, P.M., 2002. How does egg size relate to body size in butterflies? Oecologia 131, 375-379.

Fischer, K., Eenhoorn, E., Bot, A.N.M., Brakefield, P.M., Zwaan, B.J., 2003. Cooler butterflies lay larger eggs: developmental plasticity versus acclimation. Proceedings of the Royal Society of London B 270, 2051-2056.

Fischer, K., O'Brien, D.M., Boggs, C.L., 2004. Allocation of larval and adult resources to reproduction in a fruit-feeding butterfly. Functional Ecology 18, 656-663.

Fox, C.W., 1993. The influence of maternal age and mating frequency on egg size and offspring performance in Callosobruchus maculatus (Coleoptera: Bruchidae). Oecologia 96, 139-146.

Fox, C.W., Bush, M.L., Wallin, W.G., 2003. Maternal age affects offspring lifespan of the seed beetle, Callosobruchus maculatus. Functional Ecology 17, 811-820.

Fry, J.D., 2001. Direct and correlated responses to selection for larval ethanol tolerance in Drosophila melanogaster. Journal of Evolutionary Biology 14, 296-309.

Gilbert, L.E., 1972. Pollen feeding and reproductive biology of Heliconius butterflies. Proceedings of the National Academy of Sciences of the United States of America 69, 1403-1407.

Good, T.P., Tatar, M., 2001. Age-specific mortality and reproduction respond to adult dietary restriction in Drosophila melanogaster. Journal of Insect Physiology 47, 1467-1473.

Hainsworth, F.R., Precup, E., Hamill, T., 1991. Feeding, energy processing rates and eggs production in painted lady butterflies. Journal of Experimental Biology 156, 249-265.

Heberlein, U., Wolf, F.W., Rothenfluh, A., Guarnieri, D.J., 2004. Molecular genetic analysis of ethanol intoxication in Drosophila melanogaster. Integrative and Comparative Biology 44, 269-274.

Hill, C.J., Pierce, N.E., 1989. The effect of adult diet on the biology of butterflies. I. The common imperial blue, Jalmenus evagoras. Oecologia 81, 249-257.

Honda, K., Omura, H., Hayashi, N., 1998. Identification of floral volatiles from Ligustrum japonicum that stimulate flower-visiting by cabbage butterfly, Pieris rapae. Journal of Chemical Ecology 24, 2167-2180.

Jann, P., Ward, P.I., 1999. Maternal effects and their consequences for offspring fitness in the yellow dung fly. Functional Ecology 13, 51-58.

Jervis, M.A., Boggs, C., 2005. Linking nectar amino acids to fitness in butterflies. Trends in Ecology and Evolution 20, 585-587.
Kawooya, J.K., Law, J.H., 1988. Role of lipophorin in lipid transport to the insect egg. The Journal of Biological Chemistry 263, 8748-8753.

Larsen, T.B., 1991. The Butterflies of Kenya. Oxford University Press, Oxford.

Leather, S.R., 1984. The effect of adult feeding on the fecundity, weight loss and survival of the pine beauty moth, Panolis flammea (D\&S). Oecologia 65, 70-74.

Leather, S.R., 1995. Factors affecting fecundity, fertility, oviposition, and larviposition in insects. In: Leather, S.R., Hardie, J. (Eds.), Insect Reproduction. CRC Press, Boca Raton, FL, pp. 143-174.

Leavey, D.J., 2004. The evolutionary ecology of ethanol production and alcoholism. Integrative and Comparative Biology 44, 284-289.

Loher, W., Ganjian, I., Kubo, I., Stanley-Samuelson, D.W., Tobe, S.S., 1981. Prostaglandins: their role in egg-laying of the cricket Teleogryllus commodus. Proceedings of the National Academy of Sciences of the United States of America 78, 7835-7838.

Lyytinen, A., Brakefield, P.M., Lindström, L., Mappes, J., 2004. Does predation maintain eyespot plasticity in Bicyclus anynana? Proceedings of the Royal Society of London B 271, 279-283.

Mantel, N., 1967. Ranking procedures for arbitrarily restricted observations. Biometrics 23, 65-78.

May, P.G., 1985. Nectar uptake rates and optimal nectar concentrations of two butterfly species. Oecologia $66,381-386$.

McEwen, P.K., Kidd, N.A.C., 1995. The effects of different components of an artificial food on adult green lacewing (Chrysoperla carnea) fecundity and longevity. Entomologia Experimentalis et Applicata 77, 343-346.

McKenzie, J.A., McKechnie, S.W., 1979. A comparative study of resource utilization in natural populations of Drosophila melanogaster and D. simulans. Oecologia 40, 299-309.

Mevi-Schütz, J., Erhardt, A., 2003. Mating frequency influences nectar amino acid preference of Pieris napi. Proceedings of the Royal Society of London B 271, 153-158.

Mevi-Schütz, J., Erhardt, A., 2005. Amino acids in nectar enhance butterfly fecundity: a long-awaited link. The American Naturalist 165, 411-419.

Milton, K., 2004. Ferment in the family tree: does a frugivorous dietary heritage influence contemporary patterns of human ethanol use? Integrative and Comparative Biology 44, 304-314.

Molleman, F., Van Alphen, M.E., Brakefield, P.M., Zwaan, B.J., 2005a. Preferences and food quality of fruit-feeding butterflies in Kibale forest, Uganda. Biotropica 37, 657-663.

Molleman, F., Krenn, H.W., Van Alphen, M.E., Brakefield, P.M., Devries, P.J., Zwaan, B.J., 2005b. Food intake of fruit-feeding butterflies: evidence for adaptive variation in proboscis morphology. Biological Journal of the Linnean Society 86, 333-343.

Mondy, N., Corio-Costet, M.-F., 2000. The response of the grape berry moth (Lobesia botrana) to a dietary phytopathogenic fungus (Botrytis cinerea): the significance of fungus sterols. Journal of Insect Physiology 46, 1557-1564.

Moore, R.A., Singer, M.C., 1987. Effects of maternal age and adult diet on egg weight in the butterfly Euphydryas editha. Ecological Entomology 12, 401-408.

Morais, P.B., Martins, M.B., Klaczko, L.B., Mendonça-Hagler, L.C., Hagler, A.N., 1995. Yeast succession in the Amazon fruit Parahancornia amapa as resource partitioning among Drosophila spp. Applied and Environmental Microbiology 61, 4251-4257.

Murphy, D.D., Launer, A.E., Ehrlich, P.R., 1983. The role of adult feeding in egg production and population dynamics in the checkerspot butterfly Euphydryas editha. Oecologia 56, 257-263.

O'Brien, D.M., Boggs, C.L., Fogel, M.L., 2004. Making eggs from nectar: the role of life history and dietary carbon turnover in butterfly reproductive resource allocation. Oikos 105, 279-291.

Omura, H., Honda, K., 2003. Feeding responses of adult butterflies, Nymphalis xanthomela, Kaniska canace and Vanessa indica, to components in tree sap and rotting fruits: synergistic effects of ethanol and acetic acid on sugar responsiveness. Journal of Insect Physiology 49, 1031-1038. 
Omura, H., Honda, K., Hayashi, N., 2000. Identification of feeding attractants in oak sap for adults of two nymphalid butterflies, Kaniska canace and Vanessa indica. Physiological Entomology 25, 281-287.

Rattray, J.B.M., Schibeci, A., Kidby, D.K., 1975. Lipids of yeasts. Bacteriological Reviews 39, 197-231.

Rusterholz, H.-P., Erhardt, A., 2000. Can nectar properties explain sexspecific flower preferences in the Adonis blue butterfly Lysandra bellargus? Ecological Entomology 25, 81-90.

Saccheri, I.J., Bruford, M.W., 1993. DNA fingerprinting in a butterfly, Bicyclus anynana (Satyridae). Journal of Heredity 84, 195-200.

Scion Corporation, 2000. Scion Image, Release Beta 4.02. Maryland, USA.

Simmons, F.H., Bradley, T.J., 1997. An analysis of resource allocation in response to dietary yeast in Drosophila melanogaster. Journal of Insect Physiology 43, 779-788.

Smedley, S.R., Eisner, T., 1996. Sodium: a male moth's gift to its offspring. Proceedings of the National Academy of Sciences of the United States of America 93, 809-813.

Stanley-Samuelson, D.W., Loher, W., 1983. Arachidonic and other longchain polyunsaturated fatty acids in spermatophores and spermathecae of Teleogryllus commodus - significance in prostaglandin-mediated reproductive behavior. Journal of Insect Physiology 29, 41-45.

Stanley-Samuelson, D.W., Jurenka, R.A., Cripps, C., Blomquist, G.J., De Renobales, M., 1988. Fatty acids in insects: composition, metabolism, and biological significance. Archives of Insect Biochemistry and Physiology 9, 1-33.

StatSoft, Inc., 2003. Statistica for Windows. Version 6.1. Tulsa, USA.

Svoboda, J.A., 1999. Variability of metabolism and function of sterols in insects. Critical Reviews in Biochemistry and Molecular Biology 34, 49-57.
Telang, A., Booton, V., Chapman, R.F., Wheeler, D.E., 2001. How female caterpillars accumulate their nutrient reserves. Journal of Insect Physiology 47, 1055-1064.

Turunen, S., 1990. Plant leaf lipids as fatty acid sources in two species of Lepidoptera. Journal of Insect Physiology 36, 665-672.

Turunen, S., Pärnänen, S., 1987. Eicosapentaenoic acid: incorporation into phosphatidylinositol and other lipids in Pieris brassicae. Insect Biochemistry 17, 891-895.

University of Hohenheim, 1996. Department of Biological Chemistry and Nutritional Science. 〈http://www.uni-hohenheim.de/ wwwin140/INFO/ $\mathrm{LM} / \mathrm{flm} \cdot \mathrm{htm}\rangle$.

Van't Hof, A.E., Zwaan, B.J., Saccheri, I.J., Daly, D., Bot, A.N.M., Brakefield, P.M., 2005. Characterization of 28 microsatellite loci for the butterfly Bicyclus anynana. Molecular Ecology Notes 5, $169-172$.

Wang, Y., Lin, D.S., Bolewicz, L., Connor, W.E., 2006. The predominance of polyunsaturated fatty acids in the butterfly Morpho peleides before and after metamorphosis. Journal of Lipid Research 47, $530-536$.

Wei, X., Johnson, S.J., Hammond, A.M., 1998. Sugar-feeding strategy of adult velvetbean caterpillar (Lepidoptera: Noctuidae). Environmental Entomology 27, 1235-1241.

Yanagi, S.-I., Miyatake, T., 2002. Effects of maternal age on reproductive traits and fitness components of the offspring in the bruchid beetle, Callosobruchus chinensis (Coleoptera: Bruchidae). Physiological Entomology 27, 261-266.

Ziegler, R., Van Antwerpen, R., 2006. Lipid uptake by insect oocytes. Insect Biochemistry and Molecular Biology 36, 264-272. 